\title{
Incidence and predictors of surgical site infection in Ethiopia: prospective cohort
}

Tamrat Legesse Laloto', Desta Hiko Gemeda ${ }^{2}$ and Sadikalmahdi Hussen Abdella ${ }^{3 *}$

\begin{abstract}
Background: Surgical site infections are commonest nosocomial infections and responsible for considerable morbidity and mortality as well as increased hospitalizations and treatment cost related to surgical operations. The aim of this study was to determine incidence and predictors of surgical site infections at surgical ward of Hawassa University Referral Hospital, Southern Ethiopia.

Methods: We performed prospective study involving 105 patients that undergone major surgical procedure at Hawassa University Referral Hospital from March 2 to May 2, 2015. Data were extracted from paper based medical charts, operational and anesthesia note, by direct observation and patients' interview. All patients were followed daily before, during and after operation for 30 days starting from the date of operation. Data were analyzed using Statistical Package for Social Science (SPSS) for window version 20.0 software. Predictors of Surgical site infections were identified using multivariable logistic regression model. P-value less than 0.05 was considered to be statistically significant.

Result: We studied 105 patients. Sixty four patients (61\%) were males. The mean age of the patients was $30.85 \pm$ 17.72 years. The mean Body Mass Index (BMI) was $21.6 \pm 4 \mathrm{~kg} / \mathrm{m}^{2}$. Twenty patients (19.1\%) developed surgical site infections. Age greater than 40 years, $A O R=7.7(95 \% \mathrm{Cl}[1.610-40.810 p=0.016]$,$) , preoperative hospital stay more$ than 7 days, $\mathrm{AOR}=22.4(95 \% \mathrm{Cl}[4.544-110.780, p=0.001])$, duration of operation more than 1 hour, $\mathrm{AOR}=8.01(95 \% \mathrm{Cl}$ $[1.562-41.099, p=0.013])$ and administering antimicrobial prophylaxis before 1 hour of operation, $A O R=11.1(95 \% \mathrm{Cl}$ $[1.269-75.639, p=0.014]$ ) were independent predictors for surgical site infections.
\end{abstract}

Conclusion: Surgical site infection is relatively high.

Keywords: Antimicrobial prophylaxis, Surgical site infection, Predictors, Ethiopia

\section{Background}

Surgical site infections (SSI) are infections that occurs at or near surgical incision within 30 days of operation or after 1 year if implant is placed $[1,2]$. It is the 3rd commonly reported nosocomial infection accounting for 10 to $40 \%$ of all nosocomial infections [3, 4]. Globally, SSI rates have been found to be from $2.5 \%$ to $41.9 \%[3,5]$. In Western countries, 2 to $5 \%$ of patients undergoing clean surgery and up to $20 \%$ of patients undergoing intra-abdominal surgery will develop SSIs $[6,7]$. In Africa, surgical site infections were the leading infections in hospitals (pooled cumulative incidence of 5.6 per 100 surgical procedures), strikingly higher than proportions

\footnotetext{
* Correspondence: sadhussen@yahoo.com

${ }^{3}$ Pharmacology and Clinical Pharmacy Department, School of Pharmacy,

Addis Ababa University, Jimma, Ethiopia

Full list of author information is available at the end of the article
}

recorded in developed countries [8]. Another study done in Africa indicated cumulative incidence of SSIs ranged from 2.5 to $30.9 \%$ [9]. In Ethiopia, incidence rate of SSIs ranges from 10.9 to $75 \%[10,11]$.

SSIs are preventable complications following surgery and imposes significant burden in terms of patient morbidity, mortality and increased cost of treatment. Patients who develop SSIs are up to $60 \%$ more likely to spend time in an intensive care unit, 5 times more likely to be readmitted to hospital, and 2 times more likely to die compared with patients without SSIs [7, 12-14]. It account for 3.7 million excess hospital stay days, more than $\$ 1.6$ billion excess costs annually and 3.57 extra drug use $[4,13,15-18]$.

Despite improvements in operating room practices, instrument sterilization methods, better surgical technique 
and the best efforts of infection prevention strategies, surgical site infections remain a major cause of hospitalacquired infections and rates are increasing globally even in hospitals with most modern facilities and standard protocols of preoperative preparation and antibiotic prophylaxis. In developing countries where resources are limited, even basic life-saving operations, such as appendectomies and cesarean sections, are associated with high infection rates and mortality $[5,19]$. World health organization(WHO) and other studies indicated that periodic surveillance and giving feedback for surgeons on SSIs rate and associated factors can decrease up to $50 \%$ of SSIs $[7,20]$. However, studies are rare in Ethiopia regarding incidence and predictors of SSI. There is no study done in Hawassa Referal Hospital regarding incidence and predictors of SSI.

Therefore, this study aimed to show the incidence rate and predictors of SSIs in surgical ward of HURH. The result of the our study will provide base line information for surgeons, governmental and non-governmental organizations working in health care system of HURH as well as in the country to decrease incidence and in the meantime complications related with SSIs.

\section{Methods}

\section{Study design and participants}

We conducted prospective observational study in all patients that undergone major surgical procedure at surgical ward of HURH, Southern Ethiopia from March 2 to May 2, 2015. HURH serves as a main referral center for patients living in the Southern part of Ethiopia. All patients with age $\geq 1$ year admitted for elective or emergency clean and clean-contaminated surgery were included. Patients not willing to participate on the study, receiving antimicrobial during admission or stopped receiving within 48 hours before operation and patients with initial diagnosis suggestive of infection were excluded.

Clean Wound was defined as an uninfected operative wound in which no inflammation is encountered ad the respiratory, alimentary, genital or uninfected urinary tracts are not entered. In addition clean wounds are primarily closed and if necessary, drained with closed drainage. Operative incision wound that follows nonpenetrating (blunt) trauma should be included in this category if they meet the criteria.

Clean contaminated wounds was defined as operative wounds in which respiratory, alimentary, genital or urinary tracts are entered under controlled conditions and without unusual contamination. Specifically, operations involving the biliary tract, appendix, vagina and oropharynx are included in this category provided no evidence of infection or major breaks in technique is encountered.
Data were collected by two trained Nurses (BSc) not working at surgical ward using pretested data collection tool prepared by research team. The research team supervised the data collection process daily. Socio-demographic and other patient related factors were obtained directly from patients and patient's medical chart. Data on time of antimicrobial prophylaxis administration and intra-operative doses were collected by direct observation and from patients operation note. Data about antimicrobials administered after operation and duration of administration were extracted from patient medication chart and by direct observation. The variables included were age in years, gender, admission date, co-morbidity, body mass index, systemic steroid use, malnutrition, immunity status, ASA score, date of surgery, type of surgery (elective or emergency), wound class(clean or cleancontaminated), time of skin incision, duration of operation and amount of blood lost during operation. Regarding surgical antimicrobial prophylaxis used, place at which antimicrobials were administered (ward or operation room), generic name of antimicrobials, dose, time of first dose administration, route, time of intra-operative dose administration, time of postoperative dose given and duration of administration were recorded. We followed the patients and reviewed the charts daily before, during and after operation until the patients were discharged from the hospital and after discharge till 30 days since operation was done. Wound classification was done using Center for Disease Prevention and Control (CDC) criteria for surgical site infections surveillance [1].

\section{Statistical methods}

Data were coded and cleaned using Epi-Data version 3.1 and exported to SPSS for window version 20.0 for analysis. Descriptive statistics were used to present sociodemographic, surgery related factors and surgical antimicrobial prophylaxis received. We used percentages, mean, standard deviation, frequencies and cross tabulation to describe patient characteristics, operational or surgical characteristics, AMP used and to determine the relationship between dependent and independent variables. In addition, bivariate and multivariable backward logistic regression with unadjusted and adjusted odd ratio was used to identify factors associated with SSIs. Variables which have a significant association at $p$-value $<0.25$ in the bivariate logistic regression model were fitted to multivariate logistic regression model to identify predictors of SSIs. The finding was presented using unadjusted and adjusted odds ratio and their 95\% CI. P-value of less than 0.05 was considered as statistical significant in the multivariable analysis. 


\section{Ethics statement}

Ethical clearance was obtained from Jimma University, College of Health Sciences Ethical review board. We obtained permission from Hospital management before starting data collection. Written informed consent was obtained from each study participant before data collection. For Children less than 18 years written consent was obtained from the guardians. The Consent for both adults and children's were documented on prepared format. Before starting the study, the protocol including the written consent was approved by Ethical review board of Jimma University. We kept the information confidential. Patients who developed SSIs were treated according to the protocol of the hospital.

\section{Results}

Incidence of SSIs

One -hundred twenty seven patients fulfilled the inclusion criteria, of these 22 patients were excluded based on the exclusion criteria. The analysis was done on total of 105 patients that fulfilled the inclusion and exclusion criteria. Sixty four patients (61\%) were males and more than half of the patients were from rural 60(57.1\%) area. The mean age of the patients was $30.85 \pm 17.72$ years. The mean Body Mass Index (BMI) was $21.6 \pm 4 \mathrm{~kg} / \mathrm{m}^{2}$, three patients $(2.9 \%)$ were obese with $\mathrm{BMI}>=30 \mathrm{Kg} / \mathrm{m}^{2}$. Five patients $(4.8 \%)$ received blood transfusion preoperatively. Three $(2.86 \%)$ patients received systemic steroids but none of them took for more than 3 weeks. Twenty eight (26.7\%) patients were smokers. More than half of patients were under ASA score of II, 67(63.8\%). The mean preoperative hospital stay and total hospital stay of the patients were $5.59 \pm 7.78$ and $11.03 \pm 9.71$ days respectively. Out of 105 patients, 20(19.1\%) patients developed SSIs. Among patients who developed SSIs, 17(85\%) patients developed SSIs before they were discharged from hospital (Table 1).

\section{Co-morbidities}

Twelve patients (11.4\%) had one or more co-morbidities namely diabetic mellitus $4(3.8 \%)$, hypertension $4(3.8 \%)$, HIV/AIDS 3(2.9\%) and TB 1(0.9\%).

\section{Types of surgical procedure}

Head and neck procedure, 31(29.5\%) was the leading procedure followed by gastrointestinal procedure, 30(28.6\%), urologic procedure, $19(18.1 \%)$, breast procedure, $7(6.7 \%)$, hernia repair 7(6.7\%) and others (Table 2).

\section{Surgery related factors}

Sixty one (58.1\%) surgical procedures were cleancontaminated and 69(65.7\%) surgical procedures were elective. The mean duration of operation was $1.08 \pm 0.49$ and median was 1 hour. Fourteen patients (13.3\%) had history of previous surgical procedure (Table 3 ).
Table 1 Patient related factors at surgical ward of $\mathrm{HURH}$ from March 2 to May 2, 2015 ( $N=105)$

\begin{tabular}{|c|c|c|}
\hline Variables & Frequency & Percent \\
\hline \multicolumn{3}{|l|}{ Gender } \\
\hline Female & 41 & 39.0 \\
\hline Male & 64 & 61.0 \\
\hline \multicolumn{3}{|c|}{ Age categories in year } \\
\hline $1-18$ & 28 & 26.7 \\
\hline $19-40$ & 43 & 41 \\
\hline$>40$ & 34 & 32.3 \\
\hline \multicolumn{3}{|l|}{ Obesity } \\
\hline $\mathrm{BMI}<30 \mathrm{KG} / \mathrm{m}^{2}$ & 102 & 97.1 \\
\hline $\mathrm{BMI}>=30 \mathrm{~kg} / \mathrm{m}^{2}$ & 3 & 2.9 \\
\hline \multicolumn{3}{|l|}{ Residence } \\
\hline Urban & 45 & 42.9 \\
\hline Rural & 60 & 57.1 \\
\hline \multicolumn{3}{|c|}{ Preoperative blood transfusion } \\
\hline No & 100 & 95.2 \\
\hline Yes & 5 & 4.8 \\
\hline \multicolumn{3}{|l|}{ Cigarette smoking } \\
\hline No & 77 & 73.3 \\
\hline Yes & 28 & 26.7 \\
\hline \multicolumn{3}{|l|}{ ASA score } \\
\hline । & 29 & 27.6 \\
\hline$\|$ & 67 & 63.8 \\
\hline III & 9 & 8.6 \\
\hline \multicolumn{3}{|c|}{ Preoperative hospital stay } \\
\hline$<=7$ days & 78 & 74.3 \\
\hline$>7$ days & 27 & 25.7 \\
\hline
\end{tabular}

Table 2 Surgical procedures done at surgical ward of HURH from March 2 to May 2, $2015(N=105)$

\begin{tabular}{lll}
\hline Surgical procedures & Frequency & Percent \\
\hline Head and neck surgery & 31 & 29.5 \\
Breast surgery & 7 & 6.7 \\
Gastrointestinal surgery & 30 & 28.6 \\
Urological surgery & 19 & 18.1 \\
Hepato-biliary surgery & 6 & 5.7 \\
Vascular procedure & 4 & 3.8 \\
Lipoma excision & 1 & 1.0 \\
Hernia repair & 7 & 6.7 \\
Total & 105 & 100.0 \\
\hline
\end{tabular}


Table 3 Surgical related factors at surgical ward of HURH from Mach 2 to May 2, $2015(N=105)$

\begin{tabular}{llc}
\hline Variables & Frequency & Percent \\
\hline Wound class & 44 & 41.9 \\
Clean & 61 & 58.1 \\
Clean-contaminated & & \\
Surgery type & 69 & 65.7 \\
Elective surgery & 36 & 34.5 \\
Emergency & & \\
Previous surgery & 14 & 13.3 \\
Yes & 91 & 86.7 \\
No & &
\end{tabular}

\section{Predictors of surgical site infections}

On bivariate logistic regression model ten variables were associated with the occurrence SSIs at $p<0.25$. Place of residence $(p=0.080)$, age of patient greater than 40 years $(p=0.009)$, smoking $(p=0044)$, ASA score $>1 \quad(p=0.067)$ and preoperative hospital stay more than 7 days $(p<=001)$ were associated with the occurrence of SSIs. In addition, presence of one or more co-morbidities $(p=0.191)$ were associated with the occurrence of SSI (Table 4).

Clean-contaminated wound class $(p=0.191)$, previous surgery $(p=0.012)$, duration of surgery more than 1 hour $(p=0.004)$ and time of first dose AMP administration 1 hour before skin incision $(p=0.090)$ were associated with incidence of SSIs (Table 4 ).

Age above 40 years, preoperative hospital stays more than 7 days, duration of operation more than 1 hours and administering first dose of surgical antimicrobial prophylaxis before 1 hour of skin incision were independent predictors of SSIs in multivariate logistic regression analysis (Table 5).

Multivariable logistic regression analysis revealed patients with age greater than 40 years were 7.72 times more likely to develop SSIs compared with patients with age between 19 to $40, \mathrm{AOR}=7.71(95 \% \mathrm{CI}$ [1.461-40.810]). Patients who smoke cigarette were 3.70 times more likely to develop SSIs compared with patients who didn't smoke cigarette, AOR $=3.70$ (95\% CI [0.797-17.165]). Moreover, patients who stay in the hospital for more than 7 days before operation were 22.23 times more likely to develop SSIs compared to patients whose operation was done within 7 days of admission AOR $=22.23$ (95\% CI [4.544-110.781]) (Table 5).

Patients with duration of operation greater than 1 hour were 8.01 times more likely to develop SSIs compared with patients whose operation was completed within 1 hour AOR $=8.01$ (95\% CI[1.562-41.099]). Furthermore, patients whose first dose of AMP was administered before 1 hour of skin incision were 11.10 times more likely to develop SSIs compared with patients whose first dose of AMP was administered within 1 hour AOR $=11.10(95 \%$ CI[1.629-75.639]) (Table 5).

\section{Discussion}

Out of 105 patients who undergone surgical procedure, 20 patients developed SSIs which give overall incidence rate of $19.1 \%$. The finding was similar to studies done in India 20.09\% [21], Nigeria 20.3\% [22], India 21.66\% [23] and Egypt 22.6\% [24]. But, lower compared to studies done in Tanzania 26\% [5], India 33.5\% [25] and Mekele, Ethiopia 75\% [11]. The discrepancy might be due to inclusion of contaminated and dirty wound in those studies while only clean and clean-contaminated wound were included in our study. The finding was higher compared with studies done in USA 7.2\% [26], France 2.5\% [25], Egypt 9.2\% [28] and Sudan 9\% [29]. Studies done in Egypt and Sudan included only elective surgery but in our study both elective and emergency surgeries were included. This might be the reason why we find out high incidence rate of SSIs compared to studies done in both developing countries. The higher SSIs rate in present study compared to developed countries might be due modern instruments, rooms and adequate trained manpower in developed countries.

The present study revealed that patients with age greater than 40 years were 7.72 times more likely to develop SSIs compared with patients in the age range of 19 to 40 years with AOR $=7.72(95 \%$ CI[1.461$40.810, p=0.016])$. The result was in agreement with other studies $[15,27]$ confirming that as age increases the risk occurrence of SSIs increases. Different authors revealed that, as age increases the immunity will decrease and the occurrence of chronic disease that decrease the immunity of the patient, both of which synergistically predispose the patient to have SSIs [1, 10, 30].

We found that patients who smoke cigarettes were 3.7 times more likely to develop SSIs compared with patients who do not smoke cigarettes with AOR $=3.7(95 \%$ CI $[0.797-17.615, p=0.095])$ but not independent predictor for SSIs. The finding was in line with other studies $[9,20$, 22] but in studies done in Tanzania [5] and JUSH, Ethiopia [31], cigarettes smoking was found to be independent predictor for SSIs.

The sample size and observed cases with cigarettes smoking were low in our case that might be possible reason for cigarettes smoking not to be independent predictor for SSIs.

Preoperative hospital stay for longer days expose the patient for contamination or colonization by infectious pathogens which will increase risk of SSIs [1, 30]. In our study, preoperative hospital stay for more than 7 days increased the risk of SSIs by 22.44 times compared with preoperative hospital stay less than 7 days, AOR = $22.320(95 \% \mathrm{CI}[4.5544-110.781, p=0.001])$ which was in 
Table 4 Bivariate logistic regression model on factors associated with SSI at surgical ward of HURH from March 2 to May 2, 2015 (N=105)

\begin{tabular}{|c|c|c|c|c|c|}
\hline \multirow[t]{2}{*}{ Variables } & \multicolumn{5}{|c|}{ Surgical site infection } \\
\hline & $\begin{array}{l}\text { Yes N (\%) } \\
20(19.1 \%)\end{array}$ & $\begin{array}{l}\text { No N (\%) } \\
85(89.9 \%)\end{array}$ & Crude OR & $95 \% \mathrm{Cl}$ & $P$ value \\
\hline \multicolumn{6}{|l|}{ Gender } \\
\hline Male & $11(55 \%)$ & $53(62.35 \%)$ & 0.74 & $0.276-1.974$ & 0.545 \\
\hline Female & $9(45 \%)$ & $32(43.52)$ & & 1 & \\
\hline \multicolumn{6}{|l|}{ Residence } \\
\hline Rural & $15(25 \%)$ & $45(75 \%)$ & 2.67 & $0.889-7.996$ & 0.080 \\
\hline Urban & $5(11.1 \%)$ & 40(88.9) & & 1 & \\
\hline \multicolumn{6}{|l|}{ Age in year } \\
\hline $1-18$ & $2(7.1 \%)$ & $26(92.9 \%)$ & 0.59 & $0.105-3.245$ & 0.539 \\
\hline $19-40$ & $5(11.6 \%)$ & $38(88.4 \%)$ & & 1 & \\
\hline$>40$ & $13(38.2 \%)$ & $21(61.8 \%)$ & 4.71 & $1.473-15.022$ & 0.009 \\
\hline \multicolumn{6}{|l|}{ Obesity } \\
\hline $\mathrm{BMI}>=30 \mathrm{~kg} / \mathrm{m}^{2}$ & $1(33.3 \%)$ & $2(66.7 \%)$ & 2.18 & $0.188-25.354$ & 0.532 \\
\hline $\mathrm{BMI}<30 \mathrm{~kg} / \mathrm{m}^{2}$ & 19(18.6\%) & $83(81.4 \%)$ & & 1 & \\
\hline \multicolumn{6}{|c|}{ Preoperative blood transfusion } \\
\hline Yes & $1(20 \%)$ & $4(80 \%)$ & 1.07 & $0.113-10.087$ & 0.956 \\
\hline No & 19(19\%) & $81(81 \%)$ & & 1 & \\
\hline \multicolumn{6}{|l|}{ Cigarette smoking } \\
\hline Yes & $9(32.1 \%)$ & 19(67.9\%) & 2.84 & $1.027-7.866$ & 0.044 \\
\hline No & $11(14.3)$ & $66(85.7 \%)$ & & 1 & \\
\hline \multicolumn{6}{|l|}{ ASA Score } \\
\hline$>1$ & $18(23.7 \%)$ & $58(76.3 \%)$ & 4.19 & $0.907-19.360$ & 0.067 \\
\hline$<=1$ & $2(6.9 \%)$ & 27(93.1\%) & & 1 & \\
\hline \multicolumn{6}{|c|}{ Preoperative hospital stay } \\
\hline$>7$ days & $14(51.9 \%)$ & $13(48.1 \%)$ & 12.92 & $4.200-39.768$ & 0.001 \\
\hline$<=7$ days & $6(7.7 \%)$ & $72(92.3 \%)$ & & 1 & \\
\hline \multicolumn{6}{|l|}{ Co-morbidity } \\
\hline Present & $4(33.3 \%)$ & $8(66.7 \%)$ & 2.41 & $0.646-8.967$ & 0.191 \\
\hline Absent & $16(17.2 \%)$ & $77(82.8 \%)$ & & 1 & \\
\hline \multicolumn{6}{|l|}{ Diabetic mellitus } \\
\hline Yes & $1(25.0 \%)$ & $3(75.0 \%)$ & 1.44 & $0.142-14.603$ & 0.758 \\
\hline No & 19(18.8\%) & $82(81.2 \%)$ & & 1 & \\
\hline \multicolumn{6}{|l|}{ HIV/AIDS } \\
\hline Yes & $1(33.3 \%)$ & $2(66.7 \%)$ & 2.18 & $0.188-25.354$ & 0.532 \\
\hline No & 19(18.6\%) & $83(81.4 \%)$ & & 1 & \\
\hline \multicolumn{6}{|l|}{ Hypertension } \\
\hline Yes & $1(25 \%)$ & $3(75 \%)$ & 1.44 & $0.142-14.603$ & 0.758 \\
\hline No & 19(18.8\%) & $82(81.2 \%)$ & & 1 & \\
\hline \multicolumn{6}{|l|}{ Wound class } \\
\hline Clean- contaminated & $9(14.8 \%)$ & $52(85.2 \%)$ & 0.52 & $0.194-1.388$ & 0.191 \\
\hline Clean & $11(25.0 \%)$ & $33(75.0 \%)$ & & 1 & \\
\hline
\end{tabular}


Table 4 Bivariate logistic regression model on factors associated with SSI at surgical ward of HURH from March 2 to May 2, 2015 (N=105) (Continued)

\begin{tabular}{|c|c|c|c|c|c|}
\hline Emergency & $6(16.7 \%)$ & $30(83.3 \%)$ & 0.79 & $0.274-2.256$ & 0.654 \\
\hline Elective & $14(20.3 \%)$ & $55(79.7 \%)$ & & 1 & \\
\hline \multicolumn{6}{|c|}{ Previous surgery } \\
\hline Yes & $6(42.9 \%)$ & $8(57.1 \%)$ & 4.13 & $1.240-13.722$ & 0.012 \\
\hline No & $14(15.2 \%)$ & $78(84.8)$ & & 1 & \\
\hline \multicolumn{6}{|c|}{ Duration of surgery } \\
\hline$>1$ hour & 15(31.9\%) & $32(68.1 \%)$ & 4.97 & $1.649-14.974$ & 0.004 \\
\hline$<=1$ hours & $5(8.6 \%)$ & $53(91.4 \%)$ & & 1 & \\
\hline \multicolumn{6}{|c|}{ Time of fist dose AMP administered before skin incision } \\
\hline$>1$ hour & $16(24.6 \%)$ & $49(75.4 \%)$ & 2.78 & $0.853-9.030$ & 0.090 \\
\hline$<=1$ hour & $4(10.5 \%)$ & $34(89.5 \%)$ & & 1 & \\
\hline \multicolumn{6}{|c|}{ Duration of AMP administration } \\
\hline$>1$ days & $18(21.4 \%)$ & $66(78.6 \%)$ & 2.32 & $0.490-10.978$ & 0.289 \\
\hline$<=1$ day & $2(10.5 \%)$ & $17(89.5 \%)$ & & 1 & \\
\hline
\end{tabular}

line with other studies [24, 32]. In agreement with this finding, study done in Egypt indicated that there was no SSIs in patients whom the operation was done with 2 days of admission with statistically significant difference compared with patients whom operation was done after 2 days $(p=0.0034)$ [28]. This suggests that, shortening the preoperative hospital stay reduces the incidence rate of SSIs.

In present study, the incidence of SSIs was $25 \%$ in clean wound and $14.8 \%$ in clean-contaminated wound. The finding was consistence with other studies done in Tanzania which shows clean and clean-contaminated to be 63 and 33.7\% respectively [5] and in Egypt clean and clean-contaminated wounds were 57.3 and $19.5 \%$ respectively [28]. In contrast to this, in studies done in Pure and India revealed the SSIs incidence was higher in cleancontaminated wounds, $22.8 \%$ compared to clean wounds, $15.1 \%$ [30] and in Sudan clean wound was $8 \%$ and cleancontaminated was $9.5 \%$ [27]. The low incidence of SSIs in clean-contaminated wounds in present study might be due to close precaution taken to such procedures. The other possible reason might be irrational use of Ceftiaxone for most clean wound which might resulted in resistance strains in clean wound as indicated [33].

In present study, patients who had history of surgical procedures were 3.64 times more likely to develop SSIs, $\mathrm{AOR}=3.64(95 \% \mathrm{CI}[0.539-24.537])$ compared with patients who were not exposed for surgical procedure previously which was in line with other study [23]. We found prolonged operation is risk factor for SSIs because period of greatest risk for infection is the time between opening and closing the operation site $[1,30]$. In addition, it increases the extent of tissue trauma because of extensive surgical procedure, stress of prolonged anesthesia, possibility of increased blood loss and also decrease the tissue level of the surgical antimicrobial prophylaxis altogether synergistically increases the risk of SSIs $[5,30]$.

In present study, the duration of operation greater than 1 hour increased risk of SSIs by 8.01 times compared to operation completed within 1 hour, $\mathrm{AOR}=8.01$ ( $95 \%$ CI $[1.562-41.099, p=0.013])$ which was in agreement with similar studies [29, 31, 34].

The administration of the first dose of surgical antimicrobial prophylaxis before 1 hour of skin incision was observed to be independent predictor for development of SSIs in previous studies [26, 35]. In agreement with this, we found administration of first dose surgical antimicrobial prophylaxis before 1 hour of skin incision increased SSIs risk by 11.10 times compared with administration of first dose of surgical antimicrobial prophylaxis within 1 hour of skin incision $\mathrm{AOR}=$ 11.10 (95\% CI[1.629-75.639, $p=0.014]$ ). If the first dose of surgical antimicrobial prophylaxis administered 1 hour earlier to skin incision then the tissue as well as serum concentration of antimicrobials is not adequate enough to prevent contamination of the wound during the operation till the wound is closed. This rationale was confirmed by one study that indicated the low tissue concentration of antimicrobial at the time of wound closure was independent predictor for development of SSIs [36]. In present study, administration surgical antimicrobial prophylaxis for more than 24 hours was not found to be protective for SSIs with AOR $=2.78(95 \% \mathrm{CI}$ $0.853-9.030)$. The finding was in line with other studies done in different countries [27, 37,38]. Study done in USA showed that, administration of surgical antimicrobial prophylaxis for longer than recommended duration was independent predictor for development of antimicrobial 
Table 5 Multivariate logistic model on predictors of SSI at surgical ward of HURH from March 2 to May 2, 2015 (N=105)

\begin{tabular}{|c|c|c|c|c|c|}
\hline \multirow[t]{2}{*}{ Variables } & \multicolumn{5}{|c|}{ Surgical site infection } \\
\hline & $\begin{array}{l}\text { Yes N (\%) } \\
20(19.1 \%)\end{array}$ & $\begin{array}{l}\text { No N (\%) } \\
85(89.9 \%)\end{array}$ & $\begin{array}{l}\text { Crude } \\
\text { OR(95\% Cl) }\end{array}$ & $\begin{array}{l}\text { Adjusted } \\
\text { OR(95\% Cl) }\end{array}$ & $P$ \\
\hline \multicolumn{6}{|l|}{ Residence } \\
\hline Rural & $15(25 \%)$ & $45(75 \%)$ & 2.67(0.889-7.996) & $0.83(0.144-4.840)$ & 0.839 \\
\hline Urban & $5(11.1 \%)$ & 40(88.9) & & 1 & \\
\hline \multicolumn{6}{|l|}{ Age in year } \\
\hline $1-18$ & $2(7.1 \%)$ & 26(92.9\%) & $0.59(0.105-3.245)$ & $0.91(0.106-7.823)$ & 0.933 \\
\hline $19-40$ & $5(11.6 \%)$ & 38(88.4\%) & & 1 & \\
\hline$>40$ & $13(38.2 \%)$ & $21(61.8 \%)$ & $4.71(1.47-15.022)$ & $7.72(1.46-40.810)$ & 0.016 \\
\hline \multicolumn{6}{|l|}{ Cigarette smoking } \\
\hline Yes & $9(32.1 \%)$ & 19(67.9\%) & $2.84(1.027-7.866)$ & $3.70(0.797-17.16)$ & 0.095 \\
\hline No & $11(14.3)$ & $66(85.7 \%)$ & & 1 & \\
\hline \multicolumn{6}{|l|}{ ASA Score } \\
\hline$>1$ & $18(23.7 \%)$ & $58(76.3 \%)$ & 4.19(0.907-19.36) & $3.27(0.42-25.551)$ & 0.258 \\
\hline$<=1$ & $2(6.9 \%)$ & $27(93.1 \%)$ & & 1 & \\
\hline \multicolumn{6}{|c|}{ Preoperative hospital stay } \\
\hline$>7$ days & 14(51.9\%) & $13(48.1 \%)$ & $12.92(4.20-39.77)$ & $22.4(4.54-110.78)$ & 0.001 \\
\hline$<=7$ days & $6(7.7 \%)$ & 72(92.3\%) & & 1 & \\
\hline \multicolumn{6}{|l|}{ Co-morbidity } \\
\hline Present & 4(33.3\%) & $8(66.7 \%)$ & $2.41(0.646-896)$ & $1.49(0.174-12.81)$ & 0.715 \\
\hline Absent & $16(17.2 \%)$ & $77(82.8 \%)$ & & 1 & \\
\hline \multicolumn{6}{|l|}{ Previous surgery } \\
\hline Yes & $6(42.9 \%)$ & $8(57.1 \%)$ & $4.13(1.240-13.72)$ & $3.64(0.539-24.54)$ & 0.185 \\
\hline No & $14(15.2 \%)$ & 78(84.8) & 1 & 1 & \\
\hline \multicolumn{6}{|l|}{ Wound class } \\
\hline Clean-contaminated & $9(14.8 \%)$ & $52(82.2 \%)$ & $0.52(0.194-1.388)$ & $0.54(0.10-2.798)$ & 0.460 \\
\hline Clean & $11(25.0 \%)$ & $33(75.0 \%)$ & & 1 & \\
\hline \multicolumn{6}{|l|}{ Duration of surgery } \\
\hline$>1$ hour & 15(31.9\%) & $32(68.1 \%)$ & $4.97(1.649-14.97)$ & $8.01(1.56-41.099)$ & 0.013 \\
\hline$<=1$ hours & $5(8.6 \%)$ & 53(91.4\%) & & 1 & \\
\hline \multicolumn{6}{|c|}{ Time of fist dose AMP administered before skin incision } \\
\hline$>1$ hour & $16(25 \%)$ & $48(75 \%)$ & $2.78(0.853-9.030)$ & $11.10(1.63-75.64)$ & 0.014 \\
\hline$<=1$ hour & $4(10.5 \%)$ & $34(89.5 \%)$ & & 1 & \\
\hline
\end{tabular}

resistance [37]. This suggests administration of surgical antimicrobial prophylaxis for more 24 hours has no additional benefits rather increasing development of antimicrobial resistance and cost.

\section{Limitation of the study}

Our study period was short which resulted in small sample size. Variables related to health professionals, antiseptics used for patient preparation, methods used for equipment sterilization and type of anesthesia used were not included due to resource shortage.
Moreover, cases were not classified as Deep/Superficial/organ Space since these classification is not commonly practiced in the study setting.

We didn't included CDC-NNIS risk index data in the analysis since all patients has the risk index less than 2 .

Despite the limitations, our study provides vital baseline information on incidence rate and predictors of SSI in surgical ward of HURH.

\section{Conclusions}

The overall incidence rate of SSIs was $19.1 \%$ which was lower compared with report from some developing 
countries and higher compared to reports from developed countries. Age greater than 40 years old, preoperative hospital stay for more than 7 days, administrating first dose surgical antimicrobial prophylaxis before 1 hour of skin incision and duration of operation for more than 1 hour were independent predictors for SSIs. Moreover administration of surgical antimicrobial prophylaxis for more than 24 hours was not protective for SSIs. Examining and identifying high risk patients and accordingly taking all appropriate care should be done to decrease the risk of SSIs. Administration of the first dose surgical antimicrobial prophylaxis within 1 hour before skin incision and shortening the preoperative hospital stay and duration operation further decrease the incidence rate of SSIs. Prolonged administration of surgical antimicrobial prophylaxis should be avoided because antimicrobial resistance is one of global threat, which results partly due to unnecessary prolonged administration. In addition, periodic surveillance on incidence rate and predictors of SSI will further decrease the incidence rate and also further researches with long study period and with large sample size should be done to get overall predictors of SSI.

\section{Abbreviations}

AMP: Antimicrobial Prophylaxis; HURH: Hawassa University Referral Hospital; SPSS: Statistical Package for Social Sciences; SSIs: Surgical site infections

\section{Acknowledgements}

The author would like to express due appreciation for Hawassa University Referal Hospital for allowing us to access patients data. We are also grateful to Jimma University for providing us different reference materials and financial support.

\section{Funding}

The study was supported by a research grant from Jimma University[Jimma, Ethiopia]. The funders had no role in the design of the study and collection, analysis and interpretation of data and in writing the manuscript.

\section{Availability of data and materials}

The datasets during and/or analysed during the current study available from the corresponding author on reasonable request.

\section{Authors' contributions}

SH Conceived and designed the study, analysis and interpretation of data, revised it critically for important intellectual content and approved the final version. TL: acquired the data, analyzed and interpreted the data, drafted the manuscript and approved the final version. DH: analyzed the data, interpreted the data, revised it critically for important intellectual content and approved the final version.

\section{Competing interests}

The authors declare that they have no competing interests.

\section{Consent for publication}

Not applicable.

\section{Ethics approval and consent to participate}

Ethical clearance was obtained from Jimma University, College of Health Sciences Ethical review board. We obtained permission from Hospital management before starting data collection. Written informed consent was obtained from each study participant before data collection. For Children less than 18 years written consent was obtained from the guardians. The Consent for both adults and children's were documented on prepared format. Before starting the study, the protocol including the written consent was approved by Ethical review board of Jimma University. We kept the information confidential. Patients who developed SSIs were treated according to the protocol of the hospital.

\section{Author details}

${ }^{1}$ Hawassa College of Health Sciences, Hawassa, Ethiopia. ${ }^{2}$ Department of Epidemiology, Faculty of Public Health, Institute of Health Sciences, Jimma University, Jimma, Ethiopia. ${ }^{3}$ Pharmacology and Clinical Pharmacy

Department, School of Pharmacy, Addis Ababa University, Jimma, Ethiopia.

Received: 30 December 2015 Accepted: 23 December 2016

Published online: 03 February 2017

\section{References}

1. Larson EL, York N, York N, Pearson ML, Lee JT, Adams AB, et al. Guideline for prevention of surgical site infection. Infect Control Hospital Epidemiol. 1999;20(4):247-77.

2. Tietjen L, Bossemeyer D, McIntosh N. Infection Prevention: Guidelines for Healthcare Facilities with Limited Resources. Baltimore: JHPIEGO; 2003.

3. Singh R, Singla P, Chaudhary U. Surgical site infections: classification, risk factors, pathogenesis and preventive management: review article. Int J Pharma Research Health Sci. 2014;2(3):203-14.

4. AlanR S, Kavitha C. Antibiotic prophylaxis to prevent surgical site infection. Am Fam Physician. 2011;83(5):585-90.

5. Mawalla B, Mshana SE, Chalya PL, Imirzalioglu C, Mahalu W. Predictors of surgical site infections among patients undergoing major surgery at Bugando Medical Centre in Northwestern Tanzania. BMC Surg. 2011;11(1):21.

6. Kourosh A, Julie B, Tamara Ch, et al. Preventing surgical site infections Getting started kit. 2014.

7. WHO. Guideline for safe surgery. 2009. p. 69-80.

8. Allegranzi B, Bagheri Nejad S, Combescure C, et al. Burden of endemic health-care-associated infection in developing countries: systematic review and meta-analysis. Lancet. 2011;377(9761):228-41.

9. Nejad SB, Allegranzi B, Syed SB, Ellis B, Pittet D. Health-care-associated infection in Africa: a systematic review. Bull World Health Organ. 2011:89:757-65. 2011;89:757-65.

10. Mulu W, Kibru G, Beyene G, Damtie M. Associated Risk factors for Postoperative Nosocomial infections among Patients admitted at Felege Hiwot Referral Hospital, Bahir Dar, Northwest Ethiopia. Clin Med Res. 2013;2(6):140-7.

11. Mengesha RE, Kasa BG-S, Saravanan M, Berhe DF, Wasihun AG. Aerobic bacteria in post surgical wound infections and pattern of their antimicrobial susceptibility in Ayder Teaching and Referral Hospital, Mekelle, Ethiopia. BMC Res Notes. 2014;7(575):4-9.

12. Gray SH, Hawn MT. Prevention of Surgical Site Infections. Hosp Physician 2007:41-51.

13. Kirkland KB, Briggs JP, Trivette SL, Wilkinson WE, Sexton DJ. The impact of surgical site infections in the 1990s: Attributable mortality, excess length of hospitalization and extra costs. Infect Control Hosp Epidemiol. 1999;20(11):725-30.

14. Gagliardi AR, Fenech D, Eskicioglu C, Nathens AB, Mcleod R. Factors influencing antibiotic prophylaxis for surgical site infection prevention in general surgery: a review of the literature. Can J Surg. 2009;52(6):481-9.

15. Lakshmidevi N, Suchitra Joyce B. Surgical site infections: Assessing risk factors, outcomes and antimicrobial sensitivity patterns. Afr J Microbiol Res. 2009;3(4):175-9.

16. Hunt DW. The surgical infection prevention and surgical care improvement projects: national initiatives to improve outcomes for patients having surgery. Clin Infect Dis. 2006:43:322-30.

17. Lissovoy, Fraeman K, Hutchins V, Murphy D, Song D, Vaughn BB. Surgical site infection: Incidence and impact on hospital utilization and treatment costs. Am J Infect Control. 2009;1(11):1-11.

18. Rana DA, Malhotra SD, Patel VJ. Inappropriate surgical chemoprophylaxis and surgical site infection rate at a tertiary care teaching hospital. Brazilian J Infect Dis. 2013;17(1):48-53.

19. Abdel-aziz A, El-menyar A, Al-thani H, Zarour A, Parchani A, Asim M, et al. Adherence of Surgeons to Antimicrobial Prophylaxis Guidelines in a Tertiary General Hospital in a Rapidly Developing Country. Adv Pharmacol Sci. 2013;11(1).

20. Ernesto C, Starling F, Horizonte B. Applicability of the national nosocomial infections surveillance system risk index for the prediction of surgical site infections: a review. Braz J Infect Dis. 2007;11(1):134-41. 
21. Mahesh CB, Shivakumar S, Suresh BS, Chidanand SP. A Prospective study of surgical site infections in a teaching hospital. J Clin Diagn Res. 2010;4:3114-9.

22. Nwankwo EO, Ibeh IN, Enabulele O. Incidence and risk factors of surgical site infection in a tertiary health institution in Kano, Northwestern Nigeria. Int J Infect Control. 2012;8(4):8-13.

23. Kikkeri N, Setty H, Shimoga M, Halumatthigatta D, Giriyaiah S, Ramanagaram $\mathrm{N}$, et al. A study on Surgical Site Infections (SSI) and associated factors in a government tertiary care teaching hospital in Mysore, Karnataka. Int J Med Public Health. 2014;4(2):171-5.

24. Afifi IK, Labah EA, Ayad KM. Surgical site infections after elective general surgery in Tanta University Hospital: rate, risk factors and microbiological profile. Egyptian J Med Microbiol. 2009;18(2):61-72.

25. Amutha B, Viswanathan T, Science I, Association C. A retrospective study on the pattern of pathogens Isolated from Surgical Site Wound Infection in Tertiary Care Hospital in Coimbatore, India. Int Res J Med Sci. 2014:2(10):1-6.

26. Garey KW, Dao T, Chen H, Amrutkar P, Kumar N, Reiter M, et al. Timing of vancomycin prophylaxis for cardiac surgery patients and the risk of surgical site infections. J Antimicrobial Chemother. 2006;58:645-50.

27. Astagneau P, Miliani K. Non-compliance with recommendations for the practice of antibiotic prophylaxis and risk of surgical site infection: results of a multilevel analysis from the INCISO Surveillance Network. J Antimicrobial Chemother. 2009:64:1307-15.

28. Wassef MA, Hussein A, Abdul Rahman EM, El-Sherif RH. A prospective surveillance of surgical site infections: Study for efficacy of preoperative antibiotic prophylaxis. Afr J Microbiol Res. 2008;6(12):3072-8.

29. Elbur Al, Sayed A, Elsayed A, Abdel-rahman ME. Prevalence and predictors of wound infection in elective clean and clean/contaminated surgery in Khartoum Teaching Hospital, Sudan. Int J Infect Control. 2012;8(4):1-10.

30. Banashankari G S, Rudresh H K, Harsha SS. An overview of surgical site infections: an insight into the prevalence, etiology and predisposing factors. Valley Int J. 204AD;1(9):493-9.

31. Yesuf BY. Prospective evaluation of antimicrobial prophylaxis and other risk factors for surgical site infection at surgical ward. Clinc pharmaco Bipharm. 2014;3(2).

32. Fadnis MP, Desai S, Kagal A, Bharadwaj R. Surgical site infections in tertiary care hospital. Int J Healthcare Biomed Res. 2014;2(3):152-61.

33. Guta M, Aragaw K, Merid Y. Bacteria from infected surgical wounds and their antimicrobial resistance in Hawassa University Referral Teaching Hospital, Southern Ethiopia. Afr J Microbiol Res. 2014;8(11):1118-24.

34. Kasatpibal N, Nørgaard M, Sørensen HT, Schønheyder HC, Jamulitrat S, Chongsuvivatwong V. Risk of surgical site infection and efficacy of antibiotic prophylaxis: a cohort study of appendectomy patients in Thailand. BMC Infect Dis. 2006;6(1):1-7.

35. Mary T. Hawn, Joshua S. Richman, Catherine C. Vick, MS; Rhiannon J. Deierhoi, Laura A. Graham, William G. Henderson KM. Timing of Surgical Antibiotic Prophylaxis and the Risk of Surgical Site Infection. JAMA Surg. 2013;10(134):E1-8.

36. Zelenitsky SA, Ariano RE, Harding GKM, Silverman RE. Antibiotic Pharmacodynamics in Surgical Prophylaxis: an Association between Intraoperative Antibiotic Concentrations and Efficac. Antimicrob Agents Chemother. 2002:46(9):3026-30

37. Harbarth S, Samore MH, Lichtenberg D, Carmeli Y. Prolonged antibiotic prophylaxis after cardiovascular surgery and its effect on surgical site infections and antimicrobial resistance. Circulation. 2000;101:296-2921.

38. Ali M, Nadeem M, Zamen S, Shah A, Khan MM, Ahmad M, et al. Prolonged versus short course of antibiotic prophylaxis in clean general surgery. J Med Sci. 2012;20(3):128-32.

\section{Submit your next manuscript to BioMed Central and we will help you at every step:}

- We accept pre-submission inquiries

- Our selector tool helps you to find the most relevant journal

- We provide round the clock customer support

- Convenient online submission

- Thorough peer review

- Inclusion in PubMed and all major indexing services

- Maximum visibility for your research

Submit your manuscript at www.biomedcentral.com/submit
Biomed Central 